\title{
Correlates for psycho-active substance use among boarding secondary school adolescents in Enugu, South East, Nigeria
}

Pius C. Manyike ${ }^{1}$, Josephat M. Chinawa ${ }^{2 *}$, Awoere T. Chinawa ${ }^{3}$, Herbert A. Obu², Ada R.C. Nwokocha and Odutola I. Odetunde ${ }^{2}$

\begin{abstract}
Background: Psycho-active substance use among adolescents is a national and global problem and its attendant effects on adolescents cannot be overemphasized.

The objectives of this study are to determine the prevalence and pattern of psychoactive substance use among adolescents; the substances involved and the extent of the problem in this locale.

Methods: This is a cross-sectional study that assesses the pattern of psychoactive substance use among secondary school adolescents in Enugu, south East, Nigeria. The study was carried out among adolescents attending six secondary boarding schools in Enugu metropolis of Enugu State of Nigeria.

The WHO Student Drug Use Questionnaire was adapted for this study.

Data were analyzed using the Statistical Package for Social Sciences program (SPSS), version 17. Chi-square and multivariate regression were used as a test of significance for qualitative variables. A $p$-value less than 0.05 were accepted as significant for each statistical test.

Results: Out of 900, a total of 896 respondents, comprising 400 and 82 boys (482) (53.8\%) and 400 and 14 girls (414) (46.2\%) completed the questionnaires. This gave a response rate of $99.6 \%$.

The study revealed that the prevalence of current use for psychoactive substances ranges from 0.4 to $34.9 \%$ while that for life use ranges from 0.8 to $63.5 \%$. The least being cannabis and the most being kola nuts.

Kola nut is the most widely used psychoactive substance both for current use, past year use and the respondents' life time use. It shows a lifetime prevalence of $63.5 \%$ and a current use prevalence of $34.9 \%$.

More than half of the users of each of the psychoactive substances take it occasionally, using them on 1-5 days in a month. On the other hand, almost one-quarter of the users of each of the substances take it on 20 or more days in a month.
\end{abstract}

Conclusion: The study revealed that the prevalence of current use for psychoactive substances ranges from 0.4 to $34.9 \%$ while that for life use ranges from 0.8 to $63.5 \%$. The least being cannabis and the most being kola nuts.

Keywords: Adolescents, Psychoactive substance use, Nigeria

\footnotetext{
* Correspondence: josephat.chinawa@unn.edu.ng

${ }^{2}$ Department of Pediatrics, College of Medicine, University of Nigeria, Enugu Campus/University of Nigeria Teaching Hospital (UNTH), Ituku- Ozalla, Enugu State 400001, Nigeria

Full list of author information is available at the end of the article
}

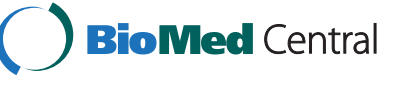

(C) 2016 Manyike et al. Open Access This article is distributed under the terms of the Creative Commons Attribution 4.0 International License (http://creativecommons.org/licenses/by/4.0/), which permits unrestricted use, distribution, and reproduction in any medium, provided you give appropriate credit to the original author(s) and the source, provide a link to the Creative Commons license, and indicate if changes were made. The Creative Commons Public Domain Dedication waiver (http://creativecommons.org/publicdomain/zero/1.0/) applies to the data made available in this article, unless otherwise stated. 


\section{Background}

Psychoactive substance use constitutes a major public health and social problem worldwide, with alcohol, tobacco and marijuana being the most commonly used. These substances are used for medicinal, social and religious purposes $[1,2]$.

In Nigeria, the National Drug Law Enforcement Agency, NDLEA, was established to curb the menace of substance use and misuse [2]. However, there are still reported increases in the trend of substance use, particularly among adolescent $[3,4]$.

Psychoactive substance use among adolescents is a national and global problem. For instance, findings from the national representative samples of US youths revealed that the lifetime prevalence of alcohol use disorders is approximately $8 \%$ and that for other substance use is $2-3 \%$ $[5,6]$. The striking increase in prevalence rates from the age of 13 to 18 years highlights adolescence as the key period of development of substance use disorders (SUDs) [5, 6].

Adolescents who use psychoactive substances run the risk of increased criminality before age twenty with frequent mental health referrals [7-9]. The use of psychoactive substances adversely affects the physical, cognitive, emotional, behavioral, social and spiritual development of the adolescents $[10,11]$. It may, for instance, be associated with public violence, financial problems, sexual difficulties and family disruption $[12,13]$.

Psychiatric manifestations may also arise from these substance use. This includes panic spells, flashbacks, psychosis, homicides, suicidal thoughts and dependence $[14,15]$.

Instances of substance use have also been reported in Nigeria. For instance, Oluwale et al. [16] in their work, for example, noted that 61.8 and $32.1 \%$ of respondents have used one or more psychoactive substances in their lifetime and in the past 1 year. In Enugu, Igwe et al. [17] noted that psychoactive substances most commonly used were alcohol (31.6\%), cola nitida (kola nut) $(20.7 \%)$ and coffee (15.7 \%).

Similar studies done in Nigeria by Oshodi et al. [18], Ene et al. [19] were about a decade ago while Igwe and Ojinnaka et al. [20, 21] did theirs about 5 years ago, however much has not been done on this topic in the past 5 years. Moreover, a careful search also showed that the work done by the above authors [18-20] was not principally among adolescents who live in boarding schools.

This study, therefore, is aimed at determining the correlates and pattern of psychoactive substance use among adolescents in boarding schools. It is hoped that the findings of this study will add to the already existing body of knowledge, and will reveal the present trend in substance use. This will also serve as a template for future studies.

\section{Definition of terms}

Kola nut with caffeine [22] as the active ingredient is from the plant species- Cola accuminata and Cola nitida [22].
Coffee is a mild stimulant and like kola nut contains caffeine [22]. It is derived from coffea canephora which occurs commonly as shrub in the forest of southern Nigeria.

\section{Methods \\ Study design}

This is a cross-sectional study that assessed the pattern of psychoactive substance use among adolescents attending boarding schools in Enugu, south East, Nigeria.

\section{Study area}

The study was carried out among adolescents aged between 15 years to 19 years attending six boarding secondary schools in Enugu metropolis.

Enugu, the capital of Enugu state of Nigeria was chosen for this study because it has many secondary schools with large adolescent population. It is made up of three local government areas, namely, Enugu East, Enugu North and Enugu South. There are 27 secondary schools in Enugu metropolis with a total population of 94,401 students. These schools are evenly distributed. The students' population of these schools cuts across the various socioeconomic strata in Nigeria. These schools were stratified into boys, girls, and mixed schools in order to get a representative sample. There are nine boys, ten girls and eight mixed schools.

Nigerian secondary education is organized into two major categories: Junior and Senior Secondary Schools each lasting for 3 years. The boarding schools are either mixed, "boys" only, or "girls" only.

\section{Questionnaire}

The WHO (World Health Organization) Student Drug Use Questionnaire [23] was adapted for this study. It was originally developed by the World Health Organization in collaboration with the United Nations Fund for substance use in different socio-cultural settings. The instrument was shown to have satisfactory validity [24].

The prototype questionnaire (WHO questionnaire, Geneva for substance use) is made up of 22 items altogether, comprising those in demographic characteristic (6 items), frequency and age at first use of ten types of psychoactive substances including alcohol and tobacco ( 14 items), and the honesty with which the questions were answered ( 2 items). See Additional file 1.

The items on parents' level of education and occupation as well as that on respondents' monthly pocket money were incorporated into the questionnaire as measures of socioeconomic status. Those on the age of the respondents at the time of divorce or death of their parents (if applicable) were aimed at estimating the proportion of students who suffered some degree of parental deprivation.

The questionnaire which was self administered was completed by the students after explanation of the purpose of 
the study. Confidentiality was assured by informing the respondents not to write their names on the questionnaire.

Adolescents who gave consent were included in this study while those who did not were excluded.

\section{Pilot study}

A pre-test was done using Command Secondary School, Abakpa Nike, Enugu, because of the ethnic and sociocultural diversity of the students' population. The aim was to identify and remove ambiguities in the survey instrument.

One hundred and fifty students participated in the pre-test. This comprised 50 students from each class of Senior Secondary 1 to Senior Secondary 3. The exercise was done after full explanation of the purpose of the exercise and the fact that confidentiality was assured. Questions and difficulties that arose during the exercise were fully explained. The average questionnaire completion time was $50 \mathrm{~min}$ with a range of 40-60 min. The researcher was present while the questionnaire was being completed. The teachers were, however, excluded from the hall. The entire questionnaire was completed and returned. On the whole, the questionnaire was adjudged valid and reliable.

\section{Study procedure}

Six schools were selected out of the twenty seven schools in Enugu metropolis through a stratified random sampling method. This comprised two boys' only schools, two girls' only schools and two mixed schools.

By stratified random selection method, a total of 150 students at each boys' and girls' school were selected by class stream.

\section{Data analysis}

All data were coded, entered, and analyzed using the Statistical Package for Social Sciences program (SPSS), version 17. Results were presented in cross tabulations and histogram. Chi-square was used to test significant association for qualitative variables while multivariate logistic regression was used to determine correlates. A $p$-value less than 0.05 was accepted as significant for each statistical test.

\section{Results}

\section{Types of substances used}

Nine hundred questionnaires were distributed. Eight hundred and ninety six of the questionnaires were analyzed, while four questionnaires were not properly filled. This gave a response rate of $99.6 \%$. Their age range was 15 years to 19 years with a mean of $15.9 \pm 1.04$ years.

The male respondents in this study were 482 (53.8\%), while the female were 414 (46.2\%). Most of the respondents $(99.1 \%)$ are Christians and $78.7 \%$ of them actively participate in religious activities as shown in Table 1. Ninety-one point one percent $(91.1 \%)$ of the respondents'
Table 1 Respondents' demographic and parental background

\begin{tabular}{lll}
\hline Characteristics & Frequency & Percentage \\
\hline Sex & 482 & 53.8 \\
Male & 414 & 46.2 \\
$\quad$ Female & & \\
Religion & 888 & 99.1 \\
Christianity & 6 & 0.7 \\
Islam & 2 & 0.2 \\
Traditional African Religion & & \\
Parental Background & 80 & 8.9 \\
Father dead & 32 & 3.6 \\
Mother dead & 106 & 11.8 \\
One or both parents dead & 23 & 2.6 \\
Parents alive but divorced & 129 & 14.4 \\
Parents deprivation & 62 & 6.9 \\
Father smokes & 3 & 0.3 \\
Mother smokes & 306 & 34.2 \\
Father takes alcohol & 130 & 14.5 \\
Mother takes alcohol & & \\
\hline & &
\end{tabular}

fathers and (96.4\%) of their mothers are alive. Only $14.4 \%$ of the respondents have parental deprivation. Parental psychoactive substance use shows that $62(6.9 \%)$ of the fathers smoke and $3(0.3 \%)$ of the mothers smoke. Also $306(34.2 \%)$ of the fathers take alcohol and 130 $(14.5 \%)$ of the mothers take alcohol.

In Table 2, five hundred and sixty nine or $63.5 \%$ of the population have ever taken kolanut. This implies that Kola nut is the most widely used psychoactive substance both for current use, past year use and the respondents' life time use. It shows a lifetime prevalence of $63.5 \%$ and a current use prevalence of $34.9 \%$. The same table revealed that the prevalence of current use for the substances ranges from 0.4 to $34.9 \%$ while that for life use ranges from 0.8 to $63.5 \%$. The least being cannabis and the most being kolanuts.

Figure 1 show that among the current users of the psychoactive substances, more than half of the users of each of the substances take it occasionally, using them on 1-

Table 2 Prevalence of past year user, current user and lifetime user of substances

\begin{tabular}{llll}
\hline Substances & $\begin{array}{l}\text { Past year use } \\
N=896\end{array}$ & $\begin{array}{l}\text { Current use } \\
N=896\end{array}$ & $\begin{array}{l}\text { Lifetime use } \\
N=896\end{array}$ \\
\hline Kolanut & $457(51.0 \%)$ & $313(34.9 \%)$ & $569(63.5 \%)$ \\
Alcohol & $435(48.5 \%)$ & $183(20.4 \%)$ & $531(59.3 \%)$ \\
Coffee & $159(17.7 \%)$ & $121(13.5 \%)$ & $176(19.6 \%)$ \\
Tobacco & $55(6.1 \%)$ & $26(2.9 \%)$ & $92(10.3 \%)$ \\
Tranquillizers & $63(7.0 \%)$ & $42(4.7 \%)$ & $90(10.0 \%)$ \\
Cannabis & $7(0.8 \%)$ & $4(0.4 \%)$ & $7(0.8 \%)$ \\
\hline
\end{tabular}




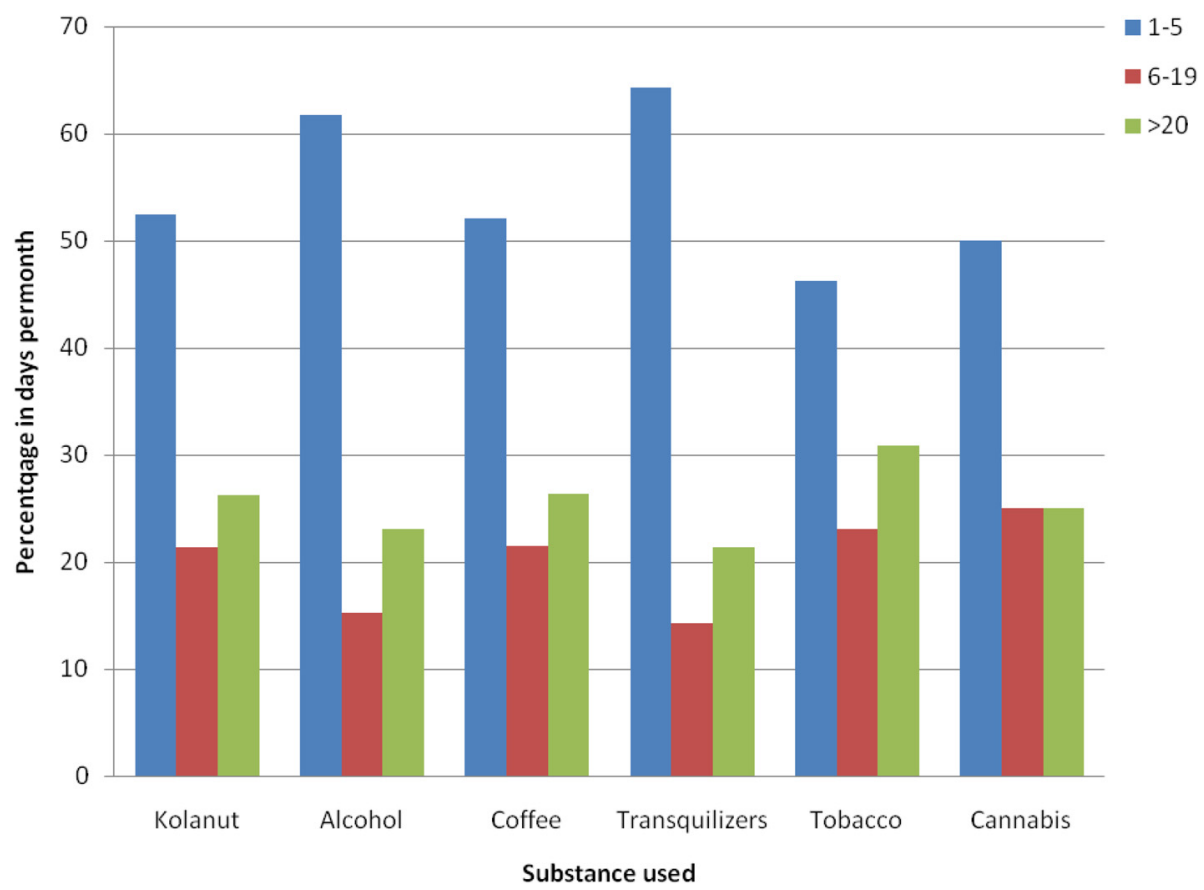

Fig. 1 Frequency of drug use in days per month based on current use

5 days in a month. On the other hand, almost one-quarter of the users of each of the substances take it on 20 or more days in a month. However, the frequency in days per month based on the current use does not depend on the substances used $(P>0.05)$.

Table 3 shows more male involvement in this substance life time use $(P<0.05)$. Cannabis was not used by any of the female respondents. However, more males than females have used all the substances.

Table 4 shows that psychoactive substance use based on life time use is dependent on the age at first use $(P<0.05)$. Majority of the respondents first used Kolanut and coffee at the age less than 10 years, alcohol, tranquilizers and tobacco at the age of 11-14 years, while cannabis at the age of $15-19$ years.

Table 5 shows that psychoactive substance use based on the life time use is dependent on the level of education at first use $p=0.05$. Majority of the respondents

Table 3 Prevalence of life time use of the various substances base on gender (sex)

\begin{tabular}{lll}
\hline Substances & $\begin{array}{l}\text { Male } \\
(n=482)\end{array}$ & $\begin{array}{l}\text { Female } \\
(n=414)\end{array}$ \\
\hline Kolanut & $474(98.3 \%)$ & $95(22.9 \%)$ \\
Alcohol & $298(61.8 \%)$ & $233(56.3 \%)$ \\
Coffee & $133(27.6 \%)$ & $26(6.3 \%)$ \\
Tranquillizers & $49(10.2 \%)$ & $41(9.9 \%)$ \\
Tobacco & $85(17.6 \%)$ & $7(1.7 \%)$ \\
Cannabis & $7(1.5 \%)$ & $0(0.0 \%)$ \\
\hline
\end{tabular}

first used Kolanut and coffee in primary school, while alcohol, tranquilizers, tobacco and cannabis were used in secondary school.

Table 6 shows no significant association between sex, age, class frequency of usage, father's education and the respondents' use of alcohol $(P>0.05)$; except mothers education and the use of alcohol $(P=0.002)$ Table 7 .

Table 7 shows stepwise logistic regression (95\% CI logistic regression of the relationship between respondents' lifetime, previous year and current use of alcohol with social class and demographic variables). Age and class have significant relationship to the respondents' lifetime use of alcohol $(P=0.000$ and $P=0.000$ respectively), while age and frequency have significant relationship to the respondents' past year use of alcohol $(P=0.001$ and $P=0.021$ respectively), and age and social class have significant relationship

Table 4 Respondents age ranges at first use of various substances based on life time use

\begin{tabular}{llll}
\hline Substances & \multicolumn{4}{l}{ Age at First Use (years) } \\
\cline { 2 - 4 } & $\leq 10$ & $11-14$ & $15-19$ \\
\hline Kolanut $(n=569)$ & $235(41.3 \%)$ & $222(39.0 \%)$ & $112(19.7 \%)$ \\
Alcohol $(n=531)$ & $192(36.2 \%)$ & $249(46.9 \%)$ & $90(16.9 \%)$ \\
Coffee $(n=159)$ & $70(44.0 \%)$ & $66(41.5 \%)$ & $23(14.5 \%)$ \\
Tranquillizers $(n=90)$ & $24(26.7 \%)$ & $51(56.7 \%)$ & $15(16.7 \%)$ \\
Tobacco $(n=92)$ & $13(14.1 \%)$ & $44(47.8)$ & $35(38.0 \%)$ \\
Cannabis $(n=7)$ & $0(0.0 \%)$ & $2(28.6 \%)$ & $5(71.4 \%)$ \\
\hline$X^{2}=62.125 \mathrm{df}=10 p$-value $=0.000$ & &
\end{tabular}


Table 5 Respondents level of education at first use of various substances based on life time use

\begin{tabular}{lll}
\hline Substances & \multicolumn{2}{l}{ Level of Education at first use } \\
\cline { 2 - 3 } & Primary School & Secondary School \\
\hline Kolanut $(n=569)$ & $334(58.7 \%)$ & $235(41.3 \%)$ \\
Alcohol $(n=531)$ & $221(41.6 \%)$ & $310(58.4 \%)$ \\
Coffee $(n=159)$ & $88(55.3 \%)$ & $71(44.7 \%)$ \\
Tranquillizers $(n=90)$ & $29(32.2 \%)$ & $61(67.8 \%)$ \\
Tobacco $(n=92)$ & $12(13.0 \%)$ & $80(87.0 \%)$ \\
Cannabis $(n=7)$ & $0(0.0 \%)$ & $7(100.0 \%)$ \\
\hline
\end{tabular}

$X^{2}=98.479 \mathrm{df}=5 p$-value $=0.000$

to the respondents' current use of alcohol $(P=0.000$ and $P=0.015$ respectively).

\section{Discussion}

The present study showed kola nut, alcohol, tranquillizers, tobacco and cannabis as the substances used by the adolescents studied. These findings, agreed with the findings of previous studies in Ilorin Nigeria [25, 26]. None of the respondents in the present study admitted having used amphetamines, cocaine, heroin, hallucinogens, opiates, barbiturates or volatile agents. This is in keeping with earlier reports where it was found that the use of these

Table 6 Association between respondents' lifetime, previous year and current use of alcohol with social class and demographic variables

\begin{tabular}{llll}
\hline Variables & Use of alcohol & \\
\cline { 2 - 4 } & Lifetime use & Previous year use & Current use \\
\hline Sex & & & \\
Male & $298(33.3 \%)$ & $248(27.7 \%)$ & $108(12.1 \%)$ \\
Female & $233(26.0 \%)$ & $187(20.9 \%)$ & $75(8.4 \%)$ \\
Age & & & \\
15 & $184(20.5 \%)$ & $145(16.2 \%)$ & $64(7.1 \%)$ \\
16 & $182(20.3 \%)$ & $153(17.1 \%)$ & $67(7.5 \%)$ \\
17 & $116(12.9 \%)$ & $96(10.7 \%)$ & $37(4.1 \%)$ \\
18 & $37(4.1 \%)$ & $32(3.6 \%)$ & $10(1.1 \%)$ \\
19 & $12(1.3 \%)$ & $9(1.0 \%)$ & $5(0.6 \%)$ \\
Class & & & $44(4.9 \%)$ \\
SS 1 & $135(15.1 \%)$ & $113(12.6 \%)$ & $82(9.2 \%)$ \\
SS 2 & $212(23.7 \%)$ & $172(19.2 \%)$ & $57(6.4 \%)$ \\
SS 3 & $184(20.5 \%)$ & $150(16.7 \%)$ & $110(8.1 \%)$ \\
Fathers Education & & & $117(13.1 \%)$ \\
Below Sec. Sch. & $229(25.6 \%)$ & $187(20.9 \%)$ & \\
Above Sec. Sch. & $302(33.7 \%)$ & $248(27.7 \%)$ & \\
Mothers Education & & & $195(21.8 \%)$ \\
Below Sec. Sch. & $242(27.0 \%)$ & \\
Above Sec. Sch. & $289(33.3 \%)$ & $240(26.8 \%)$ & $110 \%)$ \\
\hline
\end{tabular}

agents are not yet common among adolescents in Nigeria, though, some few cases have been reported [25, 26].

The present study showed that the prevalence of current use for the substances ranges from 0.4 to $34.9 \%$ while that for lifetime use ranges from 0.8 to $63.5 \%$. The least being cannabis and the most being kola nuts. The value is lower than those of previous studies. For instance, results from 2010, in the United States, showed that $48.2 \%$ of adolescents reported having used psychoactive substances at some point in their lives $[27,28]$. Some methodological differences have been identified as affecting these prevalence rates. This includes populations covered, sampling methods, and mode of data collection, survey setting, questionnaire, and estimation methods [28, 29].

Kola nut emerged the most commonly used psychoactive substance in this study both in the respondents' life time and the month preceding the study. This is because adolescents use kola nut to achieve long hours of wakefulness during examinations.

Alcohol in the present survey is the second most commonly used psychoactive substance. Earlier reports by Akpala and colleagues 1991 in Nigeria have also shown alcohol to be the second most used psychoactive substance [30]. It is pertinent to note that alcohol is widely available in Nigeria and easily accessible to various age groups. Alcohol did not show a similar trend as the other substances that showed a decline as the respondents moved from primary school to secondary school.

The fact that there is a positive correlation between respondents' alcohol use and use by the parents as shown in this study is also supported by Cleveland et al. [31]. We noted that age and socio economic class of subjects have significant relationship to the respondents' lifetime and current use of alcohol. It was noted that some mechanism could explain this variations of socioeconomic class, age and substance abuse. For instance, increased risk of alcohol use and related psychosocial problems with greater household income may reflect greater availability in such households or greater 'purchasing power' among children from such households. There may also be cultural norms to explain different alcohol behaviors across the socioeconomic spectrum [32, 33].

When multivariate logistic regression was used, we noted that age and socio economic class of subjects have significant relationship to the respondents' lifetime and current use of alcohol, thus, supporting the result of earlier study [31].

Religious participation also shows a positive correlation with respondents' intake of alcohol. A study conducted in Ireland, suggested that university students who attended religious services infrequently and university students who did not believe in God reported using more alcohol [34]. Similarly, another study in Australia found that students who believed that religion was unimportant in their lives 
Table 7 Logistic regression of the relationship between respondents' lifetime, previous year and current use of alcohol with social class and demographic variables

\begin{tabular}{|c|c|c|c|c|c|c|c|c|}
\hline \multirow[t]{2}{*}{ Variables } & \multirow[t]{2}{*}{ B } & \multirow[t]{2}{*}{ S.E. } & \multirow[t]{2}{*}{ Wald } & \multirow[t]{2}{*}{$d f$} & \multirow[t]{2}{*}{$P$-value } & \multirow[t]{2}{*}{$\operatorname{Exp}(B)$} & \multicolumn{2}{|c|}{95 \% C.I. for $\operatorname{Exp}(\mathrm{B})$} \\
\hline & & & & & & & Lower & Upper \\
\hline \multicolumn{9}{|l|}{ Lifetime Use } \\
\hline Sex & -.212 & .146 & 2.120 & 1 & .145 & .809 & 617 & 1.005 \\
\hline Age & -.521 & .080 & 42.474 & 1 & .000 & .594 & 0.511 & 679 \\
\hline Class & .769 & .113 & 45.963 & 1 & .000 & 2.158 & 2.009 & 2.310 \\
\hline Frequency & .288 & .148 & 3.801 & 1 & .051 & 1.334 & 1.277 & 1.399 \\
\hline f.edu & .264 & .151 & 3.066 & 1 & .080 & 1.302 & 1.283 & 1.325 \\
\hline m.edu & -.036 & .151 & .058 & 1 & .809 & .964 & .938 & .992 \\
\hline Constant & 7.191 & 1.213 & 35.152 & 1 & .000 & 1327.730 & & \\
\hline \multicolumn{9}{|c|}{ Previous year Use } \\
\hline Sex & -.269 & .140 & 3.721 & 1 & .054 & .764 & 698 & .834 \\
\hline Age & -.242 & .074 & 10.609 & 1 & .001 & .785 & .736 & .841 \\
\hline Class & .143 & .102 & 1.960 & 1 & .162 & 1.154 & 1.112 & 1.199 \\
\hline Frequency & .321 & .139 & 5.333 & 1 & .021 & 1.379 & 1.307 & 1.153 \\
\hline f.edu & .212 & .145 & 2.154 & 1 & .142 & 1.236 & 1.198 & 1.279 \\
\hline m.edu & -.061 & .145 & .175 & 1 & .676 & .941 & .898 & .991 \\
\hline Constant & 3.652 & 1.143 & 10.202 & 1 & .001 & 38.537 & & \\
\hline \multicolumn{9}{|l|}{ Current Use } \\
\hline Sex & -.289 & .175 & 2.730 & 1 & .098 & .749 & .713 & .787 \\
\hline Age & -.414 & .098 & 17.687 & 1 & .000 & .661 & .635 & .690 \\
\hline Class & .303 & .124 & 5.947 & 1 & .015 & 1.354 & 1.288 & 1.421 \\
\hline Frequency & .117 & .167 & .489 & 1 & .484 & 1.124 & 1.093 & 1.159 \\
\hline f.edu & .273 & .182 & 2.246 & 1 & .134 & 1.314 & 1.276 & 1.352 \\
\hline m.edu & -.119 & .182 & .426 & 1 & .514 & .888 & .842 & .933 \\
\hline Constant & 4.836 & 1.501 & 10.382 & 1 & .001 & 125.934 & & \\
\hline
\end{tabular}

reported using more alcohol, tobacco, marijuana and hallucinogens.

Dalgalarrondo et al. [35]. Furthermore, a study conducted in a university in the United States, showed that the use of ecstasy was higher among students who stated that religion had little influence on their lives [34].

In Brazil, few studies have focused on the relationship between religious involvement and substance use. The majority of the available studies have found that religiosity is protective against substance use in samples of Brazilian adolescents and a few studies have focused on this relationship among university students $[34,36]$.

Tobacco, the third psychoactive substance mostly used by the students showed a similar prevalence with that recorded in Kano (In northern Nigeria) by the NDLEA [25]. Tobacco in the form of snuff (powdered form) is enjoyed by most parents. Only few of the respondents reported use of snuff because tobacco use in the form of snuff is not fashionable among the adolescents. The adolescents who admitted using them in this study were only those whose parents use it and who only experimented with it in their homes.

In the Southern parts of the country, people frown at smoking by adolescents hence the low prevalence for both lifetime and current uses obtained in this study. It is noteworthy that result of the present study on cigarette smoking is lower than those obtained in Mexico, England and South Africa [37]. In Mexico and England, cigarette smoking is socially accepted while the high prevalence obtained in the black township of South Africa could be explained by the stress in the then apartheid South Africa which made the black boys to smoke. We also noted in this study that smaller percentage of the respondents smoked before the age of 10 years. This reflects mainly family influence, both parental and sibling.

Tranquillizers are the fifth most commonly used psychoactive substance. The current use prevalence is almost in agreement with NDLEA's $3.5 \%$ [25]. It is also important to note that students use tranquillizers such as diazepam to induce sleep after using stimulants to keep awake. 
Furthermore, we did not obtain any statistically significant difference between male and female involvement in the use of tranquillizers as against the work of Emerita et al. who showed female preponderance in the use of tranquillizers [37]. The reason for this could be due to the small sample size used by Emerita. Racial and socio-cultural differences could also explain these gender differences. Today, the commonest psychoactive substance that is found in most home medicine stores is tranquillizers. This is not unconnected with the level of stress in the society. The fact that some of the respondents used tranquillizers before 10 years of age and in primary school shows the influence of the family in introducing their children to the use of this substance.

Cannabis is the least substance used. The current prevalence almost agreed with Adelekan's 0.5 \% but differs from the high values obtained in Sokoto, Kano and Lagos (North and south west Nigeria) [25]. The low value obtained in this study may be due to under-reporting because not only that the use of cannabis is associated with psychosis and criminal activities, but that the society frowns at its use. The law in Nigeria also prohibits both the use and sales of cannabis. Though the abuse of cannabis is low, it is gradually increasing over the years [38]. Moreover, we noted that only male respondents admitted using cannabis and that all of them started the habit in secondary school. The fact that none of the female respondents admitted using cannabis in this study contradicts the reports of Faeh et al. who found an increasing female involvement in the use of cannabis [38]. It is also noted in this study that while the use of the other substances except alcohol declined as the ages of the respondents increased that of cannabis increased as their ages increased. This implies that most of the respondents give up some of their psychoactive substance use habits as they mature whereas those of them who use cannabis had their number increased instead of declining probably because they started the habit late and are yet to give it up.

Boarding schools tend to enroll a high concentration of high risk or problem prone youths who create risktaking peer networks [39]. It is noted that many of the adolescents who enroll in these schools have experienced considerable family chaos, violence, stress, and severe disruption in the formative years of their lives. Barrera et el 2001 [39] in India pointed out that boarding students who are exposed to such substances are usually not monitored by their parents at home and for some who do, are away from home for long periods.

In all, our study showed that none of the respondents is a problem drinker, majority of them drink about half a beer bottle of alcohol daily. In the same vein, none of the respondents is a heavy smoker, majority of them smoke one stick of cigarette a day. This study however, showed that a fraction of the respondents have tried to stop or reduce the use of these substances but were unable to do so. These are the respondents who have developed dependence on these drugs. About half of the respondents were initiated into psychoactive substance use by their friends, while father and mother accounted for a third and a fifth respectively. The value does not differ significantly from the $40 \%$ obtained by NDLEA [24]. The fact that none of the respondents answered the question on the fictitious psychoactive substance showed that over-reporting is not a problem in the present study.

\section{Strength and weaknesses of the study}

The sample has its strength in the sample size and number of schools selected. For the fact that this is the first time over half a decade (as much as we know) this study is carried out among adolescents in this vicinity, is worthwhile. The weakness of this study lies in the fact that a cross-sectional survey was done. A longitudinal study would have permitted the evaluation of the changing pattern of psychoactive substance use over time.

\section{Conclusion}

The study revealed that the prevalence of current use for the psychoactive substances ranges from 0.4 to $34.9 \%$ with kola nut emerging as the most commonly used psychoactive substance. There is, however, positive correlation between year of study, participation in religious activities, parental educational background and respondents' use of substance.

\section{Additional file}

Additional file 1: WHO questionnaire, Geneva for substance use (DOCX 714 kb)

\section{Abbreviations}

NDLEA, National Drug Law Enforcement Agency; SPSS, statistical package for social sciences program; SUDs, substance use disorders; WHO, World Health Organization

\section{Acknowledgements}

We acknowledge the statistician Dr Femi, who contributed in the analysis and interpretation of data.

Availability of data and materials

The data will not be shared in order to protect the participants' anonymity.

Authors' contributions

PMC, JMC, CAT, ARN and OHA, OIO contributed to the conception, writing and proof reading of this manuscript. PMC contributed to the analysis of this manuscript. All authors read and approved the final manuscript.

\section{Competing interest}

The authors declare that they have no competing interests. This study was not funded by any organization. We bore all the expense that accrued from in study.

Consent for publication

Not applicable.

Ethical approval and consent to participate

Ethical clearance was specifically approved and granted by the Ethics

Committee of the University of Nigeria Teaching Hospital, Enugu, the State 
School Board and the Principals of the selected schools. Informed verbal consent was also granted by the parents/caregivers of subjects, before enrolling them into the study.

\section{Author details}

${ }^{1}$ College of Medicine, Ebonyi State University/Department of Pediatrics, Federal Teaching Hospital, Abakiliki, Nigeria. ${ }^{2}$ Department of Pediatrics, College of Medicine, University of Nigeria, Enugu Campus/University of Nigeria Teaching Hospital (UNTH), Ituku- Ozalla, Enugu State 400001, Nigeria. ${ }^{3}$ Department Of Community Medicine, College of Medicine, Enugu State University Teaching Hospital, Enugu 400001, Enugu, Nigeria.

Received: 23 July 2014 Accepted: 2 June 2016

Published online: 09 June 2016

\section{References}

1. Burns E M. The Nature of Dependence. In: Ebie J C, Tongue EJ, editors. Handbook of the African Training Courses on Drug Dependence. Lausanne, International Council on Alcohol and Addictions ICAA 1988. p.43-52.

2. National Drug Law Enforcement Agency - NDLEA | To become the .. http://www.ndlea.gov.ng/. Nigeria's National Drug Control Master Plan (NDCMP) for 2015 to 2019 .Assessed 15 Feb 2016

3. Substance Abuse and Mental Health Services. Administration Office of Applied Studies. Preliminary results from the 1996 National Household Survey on Drug Abuse Services: H-3, DHHS publ. no. (SMA) 97-3149. Rockville, MD: SAMHSA, Office of Applied Studies; 1997.

4. Koshkina EA. Prevalence of drug-related illnesses in the Russian Federation according to official statistical data. Drug addic. 2001;3(2000):61.

5. Merikangas KR, McClair VL. Epidemiology of substance use disorders. Hum Genet. 2012;131:779-89.

6. Nutt D, King LA, Saulsbury W, Blakemore C. Development of a rational scale to assess the harm of drugs of potential misuse. Lancet. 2007;369:1047-53.

7. United Nations. Office of Drugs and Crime. World Health Organization Expert Committee on Dependence-producing Drugs.Fourteenth Report: Obtainable at http://www.who.int/substance_abuse/right_committee/en/. Accessed 22 Nov 2013

8. Vlahov D, Galea S, Resnick H, et al. Increased use of cigarettes, alcohol, and marijuana among Manhattan, New York, residents after the September 11th terrorist attacks. Am J Epidemiol. 2002;155:988-96.

9. Burke PJ, O'Sullivan J, Vaughan BL. Adolescent substance use: brief interventions by emergency care providers. Pediatr Emerg Care. 2005;1:770-6.

10. Evans, Katie; Sullivan, Michael J. Dual Diagnosis: Counseling the Mentally II Substance Abuser 2001. 2nd ed, Guilford Press 75-76.

11. Rose ME, Grant JE. Alcohol-induced blackout. J Addic Med. 2010:4:61-73.

12. Isralowitz R. Drug use: a reference handbook. Santa Barbara: ABC-CLIO; 2004. p. 122-3.

13. Abiodun OA. Drug abuse and its clinical implications with special reference to Nigeria. Centr Afr J Med. 1991;37:24-30.

14. Thun MJ, Hannan $L M$, Adams-Campbell $L L$, et al. Lung cancer occurrence in never-smokers: an analysis of 13 cohorts and 22 cancer registry studies. PLoS Med. 2008;5:185.

15. Chinawa JM, Manyike PC, Obu HA, Odetunde OI, Aniwada EC, Ndu IK, et al. Behavioral Disorder amongst Adolescents Attending Secondary School in Southeast Nigeria. Behav Neurol. 2014;2014:705835. doi:10.1155/2014/ 705835705835 .

16. Oluwole F, Olatunji FA, Olufunlayo MB. Epidemiology of psychoactive drug use amongst adolescents in metropolitan Lagos, Nigeria. Eur Child Adol Psychiatry. 2011;7:351-9.

17. Igwe WC, Ojinnaka NC. Mental health of adolescents who abuse psychoactive substances in Enugu, Nigeria - a cross-sectional study.ltal. J Pediatr. 2010;36:53

18. Oshodi OY, Aina OF, Onajole AT. Substance use among secondary school students in an urban setting in Nigeria: prevalence and associated factors. Afr J Psychiatry. 2010;13:52-7.

19. Eneh AU, Stanley PC. Pattern of substance abuse among secondary school students in rivers state. Nig J Med. 2004;13:36-9.

20. Wilson $\mathrm{Cl}$, Ngozi CO. Mental health of adolescents who abuse psychoactive substances in Enugu, Nigeria - A cross-sectional study. Ital J Pediatr. 2010;36:53.
21. Igwe WC, Ojinnaka N, Ejiofor SO, Emechebe GO, Ibe BC. Socio-demographic correlates of psychoactive substance abuse among secondary school students in Enugu, Nigeria. Eur J Soc Sci. 2009;12:277-83.

22. Jaffe JH. Drug addiction and drug abuse. In L.S. Goodman A. Gilman, editors. The pharmacological basis of therapeutics. 5th ed. New York: MacMillan. 1988;284-324.

23. The reliability and validity of the $\mathrm{WHO}$ student drug use questionnaire ... Obtainable from http://www.ncbi.nlm.nih.gov/pubmed/2606001. Accessed 22 Nov 2014

24. Adelekan ML, Odejide OA. The reliability and validity of the WHO student drug-use questionnaire among Nigerian students. Drug Alcohol Depend. 1989;24:245-9

25. National Drug Law Enforcement Agency. Drug Data Collection Unit Obtainable at https://en.wikipedia.org/wiki/National_D...Drug_Law_ Enforcement Agenc. Accessed 22 Nov 2013

26. Abiodun OA, Adelekan ML, Ogunremi OO, Oni GA, Obayan AO. Psychosocial correlates of alcohol, tobacco and cannabis use amongst secondary school students in Ilorin, Nigeria. West Afr J Med. 1994;13:213-7.

27. Substance abuse - Wikipedia, the free encyclopedia.Obtainable from http:// en.wikipedia.org/wiki/Substance_abuse. Assessed 23 Nov 2014

28. Gfroerer J, Wright D, Kopstein A. Prevalence of youth substance use: the impact of methodological differences between two national surveys. Drug Alcohol Depend. 1997;47:19-30

29. Richard AG, Anna MA, Thomas RP, Joseph CG. Discrepancies in estimates of prevalence and correlates of substance use and disorders between Two national surveys. Addict. 2007;102:623-9.

30. Akpala CO, Bolaji IBO. Drug abuse among secondary school students in Sokoto. Nig Psychopathologie Afr. 1991;23:197-204.

31. Cleveland MJ, Frederick XG, Meg G, Elizabeth AP, Gene HB. The impact of parenting on risk cognitions and risk behavior: a study of mediation and moderation in a panel of African -American adolescents. Child Dev. 2005;76:900-16.

32. Donovan JE. Estimated blood alcohol concentrations for child and adolescent drinking and their implications for screening instruments. Pediatrics. 2009;123:975-81.

33. Kelly AB, O'Flaherty M, Toumbourou JW, Connor JP, Hemphill SA, Catalano RF. Gender differences in the impact of families on alcohol use: a lagged longitudinal study of early adolescents. Addiction. 2011;106:1427-36.

34. Fernanda CG, Arthur GA, Rafael I, Alexander MA, Lúcio GO. Religion as a protective factor against drug use among brazilian university students: a national survey. Rev Bras Psiquiatr. 2013;35:29-37.

35. Dalgalarrondo P, Soldera MA, Corrêa Filho HR, Silva CA. Religion and drug use by adolescents. Rev Bras Psiquiatr. 2004;26:82-90.

36. Sanchez ZM, Opaleye ES, Chaves TV, Noto AR, Nappo SA. God forbids or mom disapproves? religious beliefs that prevent drug use among youth. J Adolesc Res. 2011:26:591-616.

37. Emerita SO, Ana RN, Zila MS, Tatiana CA, Danilo PL, Michael G, et al. Non prescribed use of tranquilizers or sedatives by adolescents: a Brazilian national survey. BMC Public Health. 2013;13:499.

38. Faeh D, Viswanathan B, Chiolero A, Warren W, Bovet P. Clustering of smoking, alcohol drinking and cannabis use in adolescents i a rapidly developing country. BMC Public Health. 2006;6:169.

39. Barrera M, Biglan A, Ary D, Li F. Replication of a problem behavior model with American Indian, Hispanic and Caucasian youth. J Early Adol. 2001;21: $133-57$

\section{Submit your next manuscript to BioMed Central} and we will help you at every step:

- We accept pre-submission inquiries

- Our selector tool helps you to find the most relevant journal

- We provide round the clock customer support

- Convenient online submission

- Thorough peer review

- Inclusion in PubMed and all major indexing services

- Maximum visibility for your research

Submit your manuscript at www.biomedcentral.com/submit 